\title{
Experimental Research on the Efficiency of Impulse Turbine Based on Ultrasonic Flow Measurement Method
}

\author{
JianWei Liu ${ }^{1, *}$, Liang Wang ${ }^{2}$, and XiaoJing Luo ${ }^{3}$ \\ ${ }^{1}$ China Datang Corporation, 100033, Beijing, China \\ ${ }^{2}$ Datang Hydropower Research Institute Corporation, Chengdu, Sichuan, China \\ ${ }^{3}$ Datang Hydropower Research Institute Corporation, Chengdu, Sichuan, China
}

\begin{abstract}
In this paper, we studied the impulse turbine of a power station based on the ultrasonic flow measurement method. Efficiency tests were carried out on the nozzle head, nozzle needle and deflector disc spring of the unit before and after the transformation. The results showed that the absolute efficiency of the unit before and after the transformation was basically the same. The efficiency value and economic performance have been improved to a certain extent, and the results obtained by using the ultrasonic method to carry out the unit efficiency test are correct and credible.
\end{abstract}

\section{Introduction}

As one of the basic test tasks of the Hydropower unit, the efficiency test of the turbine is an effective method to directly understand the running state of the turbine and master the basic power characteristics of the unit. Through the efficiency test of the unit, it is possible to evaluate the efficiency performance and output characteristics of the unit, which can provide technical data for the overhaul and transformation of the power station, and provide technical guarantee for the stable and economic operation of the power station. The ultrasonic flow measurement method can be used when measuring the flow in the efficiency test, which has the advantages of strong anti-interference ability and continuous tube installation by using the characteristics of ultrasonic ${ }^{[1,2]}$.

In this study, an impulse hydropower unit was used as an example to compare and analyze the efficiency test before and after the modification of the nozzle head, the nozzle needle and the deflector disc spring of the unit using the ultrasonic flow measurement method.

\section{Test principle}

\subsection{Flow measurement principle}

The flow measurement of the efficiency test is carried out by the ultrasonic flowmeter installed on the site of the power station. The ultrasonic flowmeter measures the flow rate by receiving the feedback of the fluid flow on the ultrasonic beam ${ }^{[3,4]}$. The average flow velocity of the fluid can be measured according to the propagation time difference between the sound waves emitted by the transmitters installed upstream and downstream in different flow directions, and then the volume flow rate of the fluid can be obtained according to the crosssectional area of the pipeline. Based on the wave recorder to collect the flow simulation signal, carry out statistical analysis, and use the computer group's passing machine flow. The flow calculation formula is as follows:

$$
V=\left(T_{1}-T_{2}\right) /\left(T_{1}+T_{2}\right) L /(2 \cos \Phi)
$$

In the formula, $\mathrm{V}$ is the average flow velocity along the direction of the sound wave; T1 is the counter current propagation time between the transducers; $\mathrm{T} 2$ is the downstream propagation time between the transducers; L is the distance between the transducers.

\subsection{Working head measurement}

The working head of the turbine is calculated by the following formula:

$$
F=\frac{p_{1}^{\prime}}{\bar{\rho}}+\bar{g} \cdot\left(z_{1^{\prime}}-z_{2}\right)+\frac{v_{1}^{2}}{2}=\frac{p_{1}^{\prime}}{\bar{\rho}}+\bar{g} \cdot Z+\frac{v_{1}^{2}}{2}
$$

In the formula, $p_{1}$ is the pressure of the water distribution loop, which can be measured by a pressure sensor with an accuracy of $0.2 \%$; $\rho$ is the weight of water, $9810\left(\mathrm{~N} / \mathrm{m}^{3}\right) ; \mathrm{v}_{1}$ is the average water velocity of the water distribution loop section $(\mathrm{m} / \mathrm{s}) ; \mathrm{g}$ is the local gravity acceleration value, which is taken as $\mathrm{m} / \mathrm{s}^{2}$ according to the altitude and latitude of the power station; 
$\mathrm{Z}$ is the water distribution loop elevation $\mathrm{Z}_{1}{ }^{\prime}$ and the nozzle axis and the bucket jet The difference between the average elevation $z_{2}$ of all intersection points of the pitch circle diameter.

\subsection{Head conversion}

In the hydraulic turbine efficiency test, due to the changes in the upstream and downstream water levels and the different flow rates at each operating point, the head loss of the diversion pipe is different, and the actual water head at each test operating point will be different. In order to calculate and sort out the characteristic curve of the unit, it is necessary to select one of the calculated heads, and then convert the actual measured values of the efficiency and flow rate of each operating point to the selected calculated head (or designated head). In order to compare the results of the two tests, the average value of the water head at each working condition of the two tests is taken as the calculated water head, which is calculated as $506.79 \mathrm{~m}$.

\section{Test results and analysis}

\subsection{Basic parameters of power station}

The basic parameters of turbine and generator are shown in Table 1 and Table 2.

Table 1. Main parameters of the turbine.

\begin{tabular}{|c|c|}
\hline \multicolumn{2}{|c|}{ Water turbine } \\
\hline Model number & CJ520-L-295/6X25.6 \\
\hline Rated output & $123 \mathrm{MW}$ \\
\hline Rated head & $482 \mathrm{~m}$ \\
\hline Maximum head & $513.8 \mathrm{~m}$ \\
\hline Minimum head & $482 \mathrm{~m}$ \\
\hline Rated speed & $300 \mathrm{r} / \mathrm{min}$ \\
\hline Runaway speed & $555 \mathrm{r} / \mathrm{min}$ \\
\hline
\end{tabular}

Table 2. Main parameters of the generator.

\begin{tabular}{|c|c|}
\hline \multicolumn{2}{|c|}{ Generator } \\
\hline Model number & SF120-20/6500 \\
\hline Rated power & $120 \mathrm{MW}$ \\
\hline
\end{tabular}

Table 3. Calculation of absolute value of hydraulic turbine before modification.

\begin{tabular}{|c|c|c|c|c|c|c|c|c|c|c|}
\hline \multicolumn{2}{|c|}{ Generator } & \multirow{2}{*}{$\begin{array}{l}\text { Pressure of } \\
\text { water } \\
\text { distribution } \\
\text { ring }\end{array}$} & \multirow[b]{2}{*}{ Flow } & \multirow[b]{2}{*}{$\begin{array}{c}\text { Working } \\
\text { head }\end{array}$} & \multicolumn{2}{|c|}{ Water turbine } & \multicolumn{4}{|c|}{ Converted to an average head of $506.79 \mathrm{~m}$} \\
\hline Power & Effectiveness & & & & Output & $\begin{array}{l}\text { Absolute } \\
\text { efficiency }\end{array}$ & Output & Flow & Effectiveness & $\begin{array}{c}\text { Water } \\
\text { consumption } \\
\text { rate }\end{array}$ \\
\hline MW & $\%$ & $\mathrm{MPa}$ & $\mathrm{m}^{3} / \mathrm{s}$ & $\mathrm{m}$ & MW & $\%$ & MW & $\mathrm{m}^{3} / \mathrm{s}$ & $\%$ & $\mathrm{~m}^{3} / \mathrm{kWh}$ \\
\hline 6.36 & 95.5 & 4.99 & 1.68 & 507.09 & 6.66 & 80.05 & 6.36 & 1.68 & 76.63 & 0.948 \\
\hline
\end{tabular}

\subsection{Test conditions and measuring point layout}

\subsubsection{Test conditions}

The efficiency test is carried out under variable load conditions, setting 5\%, 10\%, 15\%, 20\%, 25\%, 30\%, 35\%, $40 \%, 45 \%, 50 \%, 55 \%, 60 \%, 65 \%, 70 \%, 75 \%, 80 \%, 85 \%$, $90 \%, 95 \%$ and $100 \%$ rated load conditions, adopt oneway load adjustment, after each load adjustment is completed, keep for a period of time until the relevant pressure is stable before data collection. The next operating point test is performed after the data collection is completed.

\subsubsection{Measuring point layout}

The test equipment adopts HY-80 hydraulic machinery comprehensive tester, the pressure transmitter used is PTX630, with the accuracy reaches $0.5 \%$ and the accuracy of power transmitter reaches $0.2 \%$. The flow measurement adopts Shenrui Electric GER9000 ultrasonic flow measurement system, with measurement accuracy for pressure pipes can reach $\pm 0.5 \%$. The test points are as follows:

1)Unit passing flow rate;

2) Pressure of water distribution loop;

3)Unit active power;

4)Needle opening;

5)Upstream water level, downstream water level (monitored and read by the central control room).

\subsection{Test data analysis}

\subsubsection{Absolute value calculation of efficiency}

Based on the efficiency test, the turbine efficiency characteristics of the nozzle head, nozzle and deflector disc spring of a power station No. 2 unit were studied before and after the transformation, and the absolute value calculation data of the turbine efficiency (Table 3 and Table 4) were summarized. The machine efficiency is taken from the generator efficiency curve. To calculate the water head, take the average value $(506.79 \mathrm{~m})$ of the water head at each working condition of the two tests. Then compared the results of the two tests. 


\begin{tabular}{|l|l|l|l|l|l|l|l|l|l|l|}
\hline 12.09 & 95.5 & 4.97 & 3.13 & 505.34 & 12.66 & 81.77 & 12.15 & 3.13 & 78.28 & 0.933 \\
\hline 18.21 & 95.5 & 4.96 & 4.58 & 504.86 & 19.07 & 84.33 & 18.32 & 4.58 & 80.73 & 0.906 \\
\hline 24.25 & 95.5 & 4.95 & 5.97 & 503.96 & 25.39 & 86.17 & 24.45 & 5.99 & 82.49 & 0.889 \\
\hline 29.95 & 95.5 & 4.96 & 7.26 & 505.33 & 31.36 & 87.30 & 30.08 & 7.27 & 83.57 & 0.874 \\
\hline 35.58 & 96.1 & 4.96 & 8.58 & 505.56 & 37.02 & 87.19 & 35.71 & 8.59 & 84.00 & 0.869 \\
\hline 41.38 & 96.6 & 4.95 & 9.84 & 504.77 & 42.84 & 88.13 & 41.63 & 9.86 & 85.34 & 0.857 \\
\hline 47.43 & 97.0 & 4.95 & 11.17 & 505.40 & 48.90 & 88.45 & 47.63 & 11.19 & 86.01 & 0.849 \\
\hline 53.74 & 97.3 & 4.94 & 12.62 & 504.58 & 55.23 & 88.58 & 54.09 & 12.65 & 86.40 & 0.847 \\
\hline 59.13 & 97.5 & 4.94 & 13.80 & 505.26 & 60.65 & 88.83 & 59.40 & 13.82 & 86.82 & 0.842 \\
\hline 65.29 & 97.7 & 4.94 & 15.20 & 505.09 & 66.82 & 88.91 & 65.62 & 15.22 & 87.08 & 0.840 \\
\hline 72.53 & 97.8 & 4.94 & 16.83 & 506.86 & 74.15 & 88.78 & 72.51 & 16.83 & 87.06 & 0.835 \\
\hline 78.21 & 97.9 & 4.93 & 18.11 & 505.95 & 79.84 & 88.98 & 78.40 & 18.13 & 87.38 & 0.834 \\
\hline 82.57 & 98.0 & 4.91 & 19.11 & 505.02 & 84.22 & 89.15 & 83.01 & 19.14 & 87.62 & 0.835 \\
\hline 89.65 & 98.1 & 4.92 & 20.64 & 506.41 & 91.39 & 89.31 & 89.75 & 20.65 & 87.83 & 0.829 \\
\hline 95.40 & 98.2 & 4.92 & 21.90 & 507.11 & 97.14 & 89.34 & 95.30 & 21.89 & 87.95 & 0.826 \\
\hline 101.39 & 98.2 & 4.93 & 23.17 & 508.78 & 103.21 & 89.43 & 100.80 & 23.13 & 88.07 & 0.821 \\
\hline 108.05 & 98.3 & 4.91 & 24.70 & 508.81 & 109.92 & 89.36 & 107.41 & 24.65 & 88.05 & 0.821 \\
\hline 114.01 & 98.4 & 4.90 & 26.12 & 508.80 & 115.89 & 89.06 & 113.33 & 26.07 & 87.83 & 0.823 \\
\hline 119.29 & 98.4 & 4.90 & 27.43 & 509.73 & 121.23 & 88.56 & 118.25 & 27.35 & 87.36 & 0.825 \\
\hline
\end{tabular}

Table 4. Calculation of absolute value of hydraulic turbine after modification.

\begin{tabular}{|c|c|c|c|c|c|c|c|c|c|c|}
\hline \multicolumn{2}{|c|}{ Generator } & \multirow{2}{*}{$\begin{array}{l}\text { Pressure of } \\
\text { water } \\
\text { distributio } \\
\text { n ring }\end{array}$} & \multirow[b]{2}{*}{ Flow } & \multirow[b]{2}{*}{$\begin{array}{l}\text { Working } \\
\text { head }\end{array}$} & \multicolumn{2}{|c|}{ Water turbine } & \multicolumn{4}{|c|}{ Converted to an average head of $506.79 \mathrm{~m}$} \\
\hline Power & Effectiveness & & & & Output & $\begin{array}{l}\text { Absolute } \\
\text { efficiency }\end{array}$ & Output & Flow & $\begin{array}{c}\text { Effectivene } \\
\text { ss }\end{array}$ & $\begin{array}{c}\text { Water } \\
\text { consumption } \\
\text { rate } \\
\end{array}$ \\
\hline MW & $\%$ & $\mathrm{MPa}$ & $\mathrm{m} 3 / \mathrm{s}$ & $\mathrm{m}$ & MW & $\%$ & MW & $\mathrm{m} 3 / \mathrm{s}$ & $\%$ & $\mathrm{~m} 3 / \mathrm{kWh}$ \\
\hline 5.83 & 95.5 & 4.97 & 1.54 & 505.31 & 6.10 & 80.36 & 5.85 & 1.54 & 76.74 & 0.952 \\
\hline 12.18 & 95.5 & 4.97 & 3.14 & 505.69 & 12.75 & 82.27 & 12.22 & 3.14 & 78.57 & 0.929 \\
\hline 18.14 & 95.5 & 4.97 & 4.53 & 505.52 & 19.00 & 84.91 & 18.21 & 4.54 & 81.09 & 0.900 \\
\hline 24.17 & 95.5 & 4.98 & 5.89 & 506.36 & 25.31 & 86.91 & 24.20 & 5.89 & 83.00 & 0.877 \\
\hline 29.58 & 95.5 & 4.98 & 7.09 & 506.94 & 30.97 & 88.25 & 29.56 & 7.09 & 84.27 & 0.863 \\
\hline 35.23 & 96.1 & 4.97 & 8.40 & 506.50 & 36.66 & 88.18 & 35.26 & 8.41 & 84.74 & 0.859 \\
\hline 41.72 & 96.6 & 4.98 & 9.80 & 507.28 & 43.19 & 88.93 & 41.66 & 9.80 & 85.91 & 0.845 \\
\hline 47.43 & 97.0 & 4.97 & 11.08 & 506.84 & 48.90 & 89.17 & 47.43 & 11.08 & 86.49 & 0.841 \\
\hline 53.24 & 97.3 & 4.98 & 12.34 & 508.25 & 54.72 & 89.37 & 53.01 & 12.32 & 86.95 & 0.833 \\
\hline 59.89 & 97.5 & 4.97 & 13.80 & 508.54 & 61.42 & 89.61 & 59.58 & 13.78 & 87.36 & 0.828 \\
\hline 64.81 & 97.7 & 4.96 & 14.93 & 507.34 & 66.33 & 89.66 & 64.70 & 14.92 & 87.60 & 0.829 \\
\hline 72.23 & 97.8 & 4.96 & 16.61 & 508.59 & 73.84 & 89.51 & 71.85 & 16.58 & 87.56 & 0.826 \\
\hline 77.33 & 97.9 & 4.95 & 17.73 & 507.40 & 78.94 & 89.86 & 77.19 & 17.72 & 88.03 & 0.825 \\
\hline 82.83 & 98.0 & 4.93 & 18.98 & 507.02 & 84.49 & 89.92 & 82.77 & 18.97 & 88.16 & 0.825 \\
\hline 88.37 & 98.1 & 4.93 & 20.18 & 507.66 & 90.08 & 90.03 & 88.14 & 20.16 & 88.32 & 0.821 \\
\hline 94.54 & 98.2 & 4.92 & 21.56 & 507.54 & 96.27 & 90.10 & 94.33 & 21.54 & 88.48 & 0.820 \\
\hline 101.57 & 98.2 & 4.93 & 23.05 & 509.05 & 103.39 & 90.22 & 100.90 & 23.00 & 88.64 & 0.815 \\
\hline 106.47 & 98.3 & 4.90 & 24.25 & 507.34 & 108.31 & 90.14 & 106.30 & 24.24 & 88.61 & 0.820 \\
\hline 112.57 & 98.4 & 4.90 & 25.65 & 508.35 & 114.43 & 89.85 & 112.06 & 25.61 & 88.39 & 0.819 \\
\hline 118.51 & 98.4 & 4.90 & 27.12 & 509.38 & 120.44 & 89.29 & 117.61 & 27.05 & 87.86 & 0.822 \\
\hline
\end{tabular}




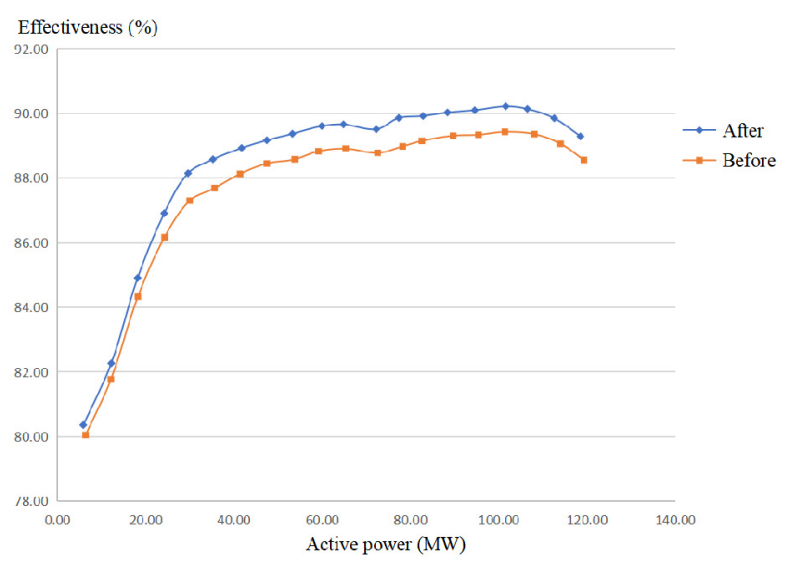

Fig. 1. Comparison diagram of turbine efficiency characteristic curve.

A comparison chart of the efficiency characteristic curve of the turbine before and after the transformation was drawn, as shown in Figure 1. It can be seen that the absolute efficiency change trend before and after the transformation is basically the same, and the efficiency value after the transformation has a certain degree of improvement. The absolute efficiency curve before and after the transformation was fitted:

The absolute efficiency curve fitting equation before transformation is:

$\mathrm{y}=-0.0000003 \mathrm{x}^{4}+0.00008 \mathrm{x}^{3}-0.0098 \mathrm{x}^{2}+0.5903 \mathrm{x}+73.265$.

The absolute efficiency curve fitting equation after transformation is:

$y=-0.0000002 x^{4}+0.00007 x^{3}-0.0089 x^{2}+0.552 x+73.207$.

\subsubsection{Economic Evaluation}

In the actual operation of the power station, in order to give full play to the potential of the unit, improve the efficiency of water energy utilization, and obtain greater benefits with less resource efficiency, it is necessary to evaluate the operating economy of the power station. Water consumption rate is often used as the basis for economic evaluation. It is defined as the amount of water consumed per unit of power generation, in $\mathrm{m}^{3} / \mathrm{kWh}$. Based on the efficiency test data, the water consumption rate is converted to the average head to compare the results of the two tests. The calculated water consumption rate is shown in Table 5, and the water consumption rate curve comparison chart is drawn as shown in Figure 2.

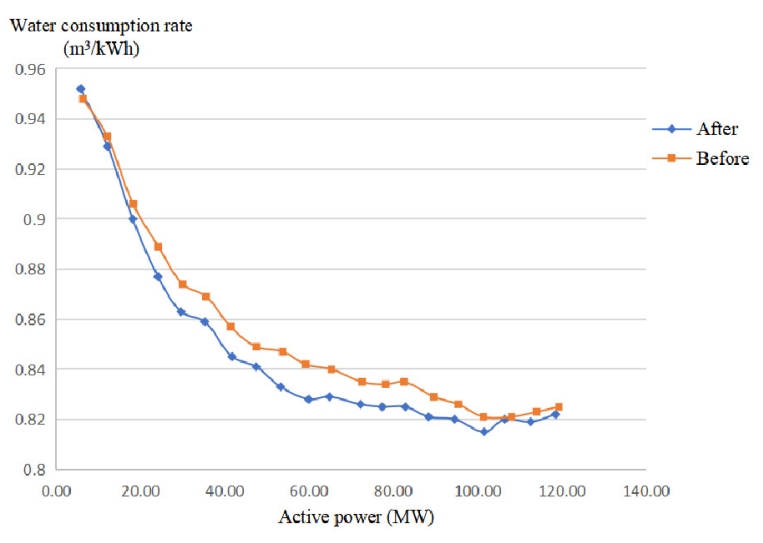

Fig. 2. Comparison chart of water consumption rate curve.

Table 5. Comparison of water consumption rate before and after modification.

\begin{tabular}{|c|c|c|c|}
\hline \multicolumn{2}{|c|}{ Before transformation } & \multicolumn{2}{|c|}{ After transformation } \\
\hline $\begin{array}{c}\text { Power } \\
(\mathrm{MW})\end{array}$ & $\begin{array}{c}\text { Water } \\
\text { consumpti } \\
\text { on rate } \\
\left(\mathrm{m}^{3} / \mathrm{kWh}\right)\end{array}$ & $\begin{array}{c}\text { Power } \\
(\mathrm{MW})\end{array}$ & $\begin{array}{c}\text { Water } \\
\text { consumpti } \\
\text { on rate } \\
\left(\mathrm{m}^{3} / \mathrm{kWh}\right)\end{array}$ \\
\hline 6.36 & 0.948 & 5.83 & 0.952 \\
\hline 12.09 & 0.933 & 12.18 & 0.929 \\
\hline 18.21 & 0.906 & 18.14 & 0.900 \\
\hline 24.25 & 0.889 & 24.17 & 0.877 \\
\hline 29.95 & 0.874 & 29.58 & 0.863 \\
\hline 35.58 & 0.869 & 35.23 & 0.859 \\
\hline 41.38 & 0.857 & 41.72 & 0.845 \\
\hline 47.43 & 0.849 & 47.43 & 0.841 \\
\hline 53.74 & 0.847 & 53.24 & 0.833 \\
\hline 59.13 & 0.842 & 59.89 & 0.828 \\
\hline 65.29 & 0.840 & 64.81 & 0.829 \\
\hline 72.53 & 0.835 & 72.23 & 0.826 \\
\hline 78.21 & 0.834 & 77.33 & 0.825 \\
\hline 82.57 & 0.835 & 82.83 & 0.825 \\
\hline 89.65 & 0.829 & 88.37 & 0.821 \\
\hline 95.40 & 0.826 & 94.54 & 0.820 \\
\hline 101.39 & 0.821 & 101.57 & 0.815 \\
\hline 108.05 & 0.821 & 106.47 & 0.820 \\
\hline 114.01 & 0.823 & 112.57 & 0.819 \\
\hline 119.29 & 0.825 & 118.51 & 0.822 \\
\hline
\end{tabular}

For hydropower units, the main factors affecting water consumption rate are turbine efficiency and working head. Under the same conditions, the higher the efficiency of the unit, the lower the water consumption rate. It can be seen from Figure 2 that the change trend of the water consumption rate before and after the renovation is basically the same, and the water consumption rate after the renovation has been reduced to a certain extent, indicating that the economic performance of the unit has improved after the renovation. From the perspective of unit economy, the optimal economic operation area of the unit is 60MW 120MW. 


\subsubsection{Error Analysis}

1) In the efficiency test, the detection error of the pressure sensor of the water distribution loop is $0.5 \%$, and the calculation error including the flow head is $1 \%$. After square root synthesis, the calculated head error is: $\pm 1.118 \%$.

2) The efficiency test measurement of active power uses a power transmitter with an accuracy level of 0.2. According to the procedures of IEC60041 and $\mathrm{GB} / \mathrm{T} 20043$, the system error of electric power measurement is $0.78 \%$ when the confidence level is $95 \%$ in high-precision measurement occasions.

3) The efficiency test uses an ultrasonic flowmeter to measure flow, and its accuracy depends on the calibration accuracy and flow measurement accuracy of the ultrasonic flowmeter. According to the information provided by the flowmeter manufacturer and combined with the on-site situation, the error is $\pm 0.5 \%$.

From the above, it can be concluded that the system error of the efficiency test is $\pm 1.45 \%$. According to the estimated value of efficiency standard deviation, the random error of efficiency test is $\pm 0.75 \%$.

Finally, the comprehensive error of the efficiency test is: $\mathrm{fn}= \pm \sqrt{ }(\mathrm{fns} 2+\mathrm{fnr} 2)= \pm 1.63 \%$.

\section{Conclusion}

1) Based on the ultrasonic flow measurement method, an efficiency test was carried out before and after the transformation of a power plant unit. The results showed that the absolute efficiency change trend before and after the transformation was basically the same, and the efficiency value was improved to a certain extent after the transformation. According to the test data, the absolute efficiency curve equation before and after the transformation is fitted to guide the operation of the power station.

2) Based on the efficiency test data, the economic performance of the unit was analyzed, and the results showed that the change trend of the water consumption rate before and after the transformation was basically the same. From the perspective of unit economy, the optimal economic operation area of the unit is divided into $60 \mathrm{MW} \sim 120 \mathrm{MW}$.

3) Judging from the results of the efficiency test, the results obtained by the unit efficiency test using the ultrasonic method are correct and credible. The total error of the efficiency test is $1.63 \%$, which meets the requirements of $\pm 1.5 \%$ to $\pm 2.5 \%$ specified in the IEC regulations.

\section{References}

1. B.T Zou, B. Wu, B. Lin. Scientific and Technological Innovation. J. 5, 191-192 (2021)

2. Yongfa Su. New Technology \& New Products of China. J. 15, 75-77 (2020)

3. L. Qu, J.H. Yun. Yangtze River, J. 50, 172-175+191 (2019)
4. G.H. Ma, Yunnan Electric Power. J. 47, 22-25 (2019) 